\title{
Modos DE APROPRIAÇÃo DO GÊNERO DEBATE REGRADO NA ESCOLA: UMA ABORDAGEM APLICADA*
}

(The production process of the genre debate in the mother language teaching and learning context: an applied approach)

\author{
Sandoval Nonato Gomes-SAnTos \\ (Universidade Federal do Pará)
}

\begin{abstract}
RESUMO: Este estudo propõe descrever e analisar o processo de produção do gênero debate regrado, no contexto de práticas de ensino-aprendizagem de língua materna, em turmas de Ensino Médio de uma escola pública de Belém (PA). Trata-se de compreender os modos com que o gênero mencionado, instituído objeto de ensino, se disciplinariza, ou seja, o estatuto que adquire quando inscrito na ordem da disciplina escolar Lingua Portuguesa. Para tanto, optamos por focalizar a atividade do aluno, mais especificamente os dispositivos pelos quais ele se inscreve no gênero ensinado, o que implica em considerar não apenas os modos com que se apropria do mesmo, mas suas percepçoes sobre a própria tarefa com que se acha envolvido.

PALAVRAS-CHAVE: debate regrado; ensino-aprendizagem do português; gênero.
\end{abstract}

ABSTRACT: The genre debate has its own particular rules. This study describes and analyses the production process of the genre debate in the mother language teaching and learning context, in High School juniors groups of a public school in Belém (PA). The aim of the study is to understand how this genre, as a teaching object, assumes the role of discipline content, that is, its status in the Portuguese language class. Students' productions, specifically the roles they assume to perform in this genre, are focused on. This focus implies considering not only the ways in which students learn the genre, but also their perceptions about the tasks they are involved in achieving.

KEY-WORDS: debate; teaching and learning of Portuguese; genre.

* As reflexões propostas neste estudo foram instigadas pelo diálogo que estabeleci com os pesquisadores da Faculdade de Psicologia e Ciências da Educação da Universidade de Genebra (FPSEUNIGE), quando da realização de um Pós-Doutorado (Bolsa Capes - BEX 2724/05-7), entre maio e julho de 2006. Minha gratidão ao GRAFE (Groupe de Recherche en Analyse du Français Enseigné), especialmente a Bernard Schneuwly, Joaquim Dolz e Glaís Cordeiro.

D.E.L.T.A., 25:1, 2009 (39-66) 


\section{Introdução}

A pesquisa sobre o conceito de gênero discursivo, considerados os estudos da linguagem brasileiros na última década do século passado e no início dos anos 2000 (v. Gomes-Santos 2004a, 2004b, 2005a), tem permitido a constituição de direções de pesquisa articuladas em torno de questões de ordem teórica, metodológica e aplicada. Uma parte dessas direções de pesquisa tem-se procurado basear no registro, na descrição e na análise de práticas de produção-recepção de gêneros em campos institucionais determinados, tal qual o campo das práticas de letramento escolares.

No que se refere particularmente à abordagem de gênero como "objeto de ensino", a consideração de práticas situadas de apropriação de determinados gêneros amplia uma das tendências bastante prestigiadas na reflexão sobre o conceito, exatamente aquela relacionada à caracterização ou descrição de gêneros com base na análise de seu funcionamento e de sua organização textual, enunciativa ou discursiva (v. Gomes-Santos 2004a). Reenfocando essa tendência, a atenção às práticas de recepção-produção de gêneros supõe, do ponto de vista teórico, que o funcionamento de determinados fenômenos da linguagem se constrói e se atualiza na dinâmica das interações didáticas em que o gênero adquire pertinência, e não como estabilização de propriedades a ele supostamente inerentes. Tal pressuposto traz implicações, por sua vez, tanto em termos metodológicos, quanto em termos mais propriamente aplicados.

Do ponto metodológico, investigar as práticas de recepção-produção de gêneros coloca questões significativas, por exemplo, no que se refere aos procedimentos de geração, ordenação, descrição e análise de dados. Nesse caso, parece ser exatamente a atenção às práticas de produção-recepção de gêneros - o que implica o investimento no acompanhamento das mesmas em sua complexidade constitutiva - que nos pode permitir problematizar um certo pendor taxionômico e prescritivista que marca historicamente tanto a teorização sobre a questão dos gêneros quanto a apropriação dessa teorização para o ensino: com efeito, seja no domínio da pesquisa acadêmica seja naquele das práticas escolares, não é raro que os gêneros sejam tomados como construtos abstratos - ou como categoria taxionômica com fins de classificação, oralização, compreensão ou escrita de textos.

Já no que diz respeito à dimensão aplicada da reflexão sobre as práticas de produção-recepção de gêneros, as implicações de tal investimento 
relacionam-se ao lugar central que se busca atribuir aos dispositivos de transposição didática (Chevallard 1985; Bronckard \& Plazaola Giger 1998; Schneuwly 1995) de gêneros para as práticas de ensino-aprendizagem da língua na escola. A modelização didática, ou seja, a construção desses dispositivos - chamados de "modelos didáticos" (De Pietro \& Schneuwly 2002) que se materializam em sequiências didáticas - aparece como condição de possibilidade do próprio ensino. Nos termos de De Pietro e Schneuwly, "o modelo didático do saber é portanto um pressuposto da ensinabilidade do saber"1. Assim, a idéia de que é necessário pensar os gêneros no processo de uma "engenharia didática" (De Pietro \& Schneuwly 2002) parece significativa na medida em que supera o caráter acessório de que se investe, não raro, a dimensão didática quando da reflexão sobre o conceito de gênero no domínio da pesquisa acadêmica. A esse propósito, cabe a percepção de Rojo (2001a: 316), que assinala:

(...) muitas de nossas ações de reflexão junto aos professores têm-se voltado ao nosso campo específico - a linguagem, a língua, as práticas de linguagem, o letramento e descurado, pelo menos parcialmente, dos aspectos propriamente didáticos da implementação das teorias numa prática escolar. ${ }^{2}$

Considerando-se as motivações de ordem teórica, metodológica e aplicada implicadas na discussão sobre as práticas de recepção-produção de gêneros, e na continuidade das reflexões propostas em trabalho anterior (Gomes-Santos 2005b), este estudo propõe descrever e analisar o processo de produção do gênero debate regrado, no contexto de práticas de ensinoaprendizagem de língua materna, em turmas de Ensino Médio de uma escola pública de Belém (PA). Trata-se do propósito de expor o processo de produção do gênero mencionado, enfocando especificamente os dispositivos pelos quais os alunos se inscrevem nesse gênero, o que implica não

1 A tradução de obras citadas - no caso de obras não traduzidas para o português - deve ser considerada de nossa responsabilidade.

2 Ao relatar uma experiência de formação de professores, a autora coloca em questão um dos pressupostos tornado consenso na discussão sobre o ensino - a idéia de que o ponto nevrálgico no incremento das práticas de ensino decorreria unicamente de um déficit na formação teórica do professor, isto é, da ausência de uma formação adequada no que se refere à apropriação de avanços teóricos das disciplinas de referência. Para ela, a isso se acresce inextricavelmente a carência de dispositivos que contemplem a dimensão didática da formação do professor, ou seja, a dimensão relativa aos modos de modelização do saber com vistas a torná-lo saber a ser ensinado. Assim, para Rojo (2001a: 334), "a questão didática, no caso de um lingüista aplicado, deverá ser muito mais seriamente levada em conta, embora essa seja uma de nossas áreas adjetivas e não a substância de nossa formação". 
apenas os modos com que se apropriam do mesmo mas suas percepções sobre a própria tarefa com que se acham envolvidos.

Do ponto de vista mais propriamente teórico, este trabalho supõe a possibilidade de conjugar contribuições dos estudos aplicados voltados para questões de ordem didático-pedagógica (ver, por exemplo, Rojo 2001a, $2001 b, 2001 c)$ com os estudos enunciativo-discursivos, fundados em uma concepção dialógica de linguagem tal qual proposta no pensamento bakhtiniano (Bakhtin/Volochínov [1923] 1979, Bakhtin [1952-3] 2003). Essa opção geral aponta para a complementaridade entre a reflexão sobre os dispositivos didáticos implicados nas práticas escolares de uso da linguagem e a abordagem dos mecanismos lingüísticos (enunciativo-discursivos) a elas associados.

\section{O gênero debate regrado como objeto de ensino}

O gênero debate foi objeto de interesse de vários estudos. No que respeita particularmente a sua consideração como objeto de ensino, o debate ganhou ampla teorização por meio das investigações propostas pela equipe de Didática de Línguas da Seção de Ciências da Educação da Universidade de Genebra (v. De Pietro, Erard e Kaneman-Pougatch 1996/7; De Pietro e Schneuwly 1999; Dolz e Schneuwly 1998; Dolz, Moro e Pollo 2000; Schneuwly e Dolz 2004). O que de comum vincula esses estudos é exatamente a dimensão didática de que se investe a reflexão sobre o gênero. Trata-se de um interesse que busca não apenas descrever e analisar os modos de apropriação do gênero no contexto escolar, mas também refletir sobre as implicações que o conhecimento desses modos de apropriação pode trazer para o incremento das práticas de ensino-aprendizagem de língua. Nessa direção, a dimensão didática dos estudos mencionados consiste também em uma dimensão propositiva, e mesmo intervencionista, na medida em que investigar as práticas de apropriação supõe a reflexão sobre alternativas de intervenção didática.

$\mathrm{Na}$ abordagem que fazem do debate regrado ${ }^{3}$, os autores estão de acordo que a variante escolar do debate deve privilegiar mais a construção con-

\footnotetext{
3 É curioso que os autores marquem a adjetivação regrado [régulé ] relacionando-a à variante escolar do gênero debate, embora reconheçam que a dimensão regrada é constitutiva desse gênero tal como ele circula em práticas sociais diversas, não apenas na esfera escolar.
} 
junta de um ponto de vista sobre um assunto do que as dimensões polêmicas do debate. Dolz e Schneuwly (1998), por exemplo, ao descreverem e analisarem intervenções didáticas voltadas para o ensino-aprendizagem do debate, definem o gênero como "uma discussão que se plasma (qui porte) sobre argumentos", e mais, como "a construção conjunta de uma resposta complexa a (uma) questão". Com base nessa definição geral, os autores assinalam que

Um debate público se volta sempre para uma questão controversa e permite a intervenção de diversos parceiros que exprimem suas opiniões ou atitudes, tentando modificar aquelas dos outros pelo ajuste das suas próprias, em vista, idealmente, de construir uma resposta comum à questão inicial. Pode ser chamado de regrado quando um moderador gere e estrutura seu desenrolar evidenciando a posição de diferentes debatedores, facilitando as trocas entre eles e tentando eventualmente arbitrar os conflitos e conciliar as posições opostas. Desse ponto de vista, o moderador não assume somente o papel de mediador entre os participantes, mas também (e, às vezes, principalmente) entre os participantes e o auditório. (Dolz e Schneuwly 1998: 166).

Em outros termos, para que haja um debate faz-se necessário:

- a presença de um argumento que baseia uma posição positiva ou negativa em relação à questão inicial do debate: (posição a favor ou contra a mistura na escola);

- seu estatuto quanto ao que foi dito anteriormente: concordância, apoio com ou sem aprofundamento ou, ao contrário, desacordo, refutação etc.

- a maneira com que se vincula argumento e posição: ilustração, exemplo, recurso aos fatos, recurso às 'leis' (naturais, sociais, lógicas, jurídicas etc.), experiência, causalidade, significação etc. (Dolz e Schneuwly 1998: 167-8).

Considerando-se que a modelização didática do gênero - isto é, a eleição, entre suas dimensões constitutivas, daquelas que serão objeto de ensino-aprendizagem - é condição imprescindível para a própria ensinabilidade desse gênero, cabe atentar para o privilégio, na elaboração didática proposta pelos autores, à construção conjunta de um ponto de vista sobre um assunto do que às dimensões polêmicas do debate.

Trata-se de uma opção que permite evitar o foco em uma dimensão bastante freqüente do gênero debate quando é produzido, por exemplo, no campo do político: a dimensão, diríamos, panfletária, materializada em estratégias de convencimento que se utilizam, entre outros, de má fé e falso testemunho, ou da agressão direta. É essa dimensão que parece justificar a primazia, freqüente em determinados eventos de enunciação polêmica, da tomada de posição baseada no binômio sim ou não, o que impede a consi- 
deração do processo de construção dessa polêmica que supõe fundamentalmente, como propõe Maingueneau (1984), um acordo sobre uma base comum. Assim, assumir um posicionamento seria partilhar um universo de referência comum com o outro; em outros termos, reconhecer o outro como interlocutor efetivo daquilo que lhe digo, ouvi-lo como interlocutor que é legítimo em seu gesto de dizer e, finalmente, reconhecer em quais motivações se funda o dizer-posicionamento do outro. Tomada nesses termos como processo de construção de pontos de vista e, com base neles, de posicionamentos, e não como oralização de $\operatorname{sim}$ ou não -, a enunciação polêmica constitutiva do gênero debate parece ir ao encontro do pressuposto que considera a escola em sua função fundamentalmente educativa ${ }^{4}$.

Em direção similar à dos autores, De Pietro, Erard e Kaneman-Pougatch (1996/7) enfatizam o estatuto "modelizado" de que se investe o gênero quando de sua consideração como um gênero a ser ensinado. Nessa direção, os autores descrevem o percurso metodológico de construção exatamente do que chamam de modelo didático do gênero. A construção de um tal modelo orienta-se segundo um movimento que inicia na constituição de um saber sobre o que os alunos já conhecem sobre o gênero e se articula com a análise das características de debates que ocorrem em espaços sociais que não a escola. A esses procedimentos, acresce-se os aportes de teorias que tomaram o debate - e principalmente a dimensão argumentativa dele constitutiva - como objeto de investigação. Com base nessas informações, os autores propõem a caracterização do que seria um modelo "ensinável" do gênero. Tal modelo é o mecanismo que permite a construção de seqüências didáticas de ensino-aprendizagem do gênero em questão e a diferenciação dessas seqüências conforme o grau de letramento escolar em que se encontram os alunos.

Dolz, Moro e Pollo (2000), por sua vez, enfocam exatamente o processo de apropriação do gênero no quadro de uma seqüência didática. Tratase de um estudo comparativo que enfatiza os efeitos do ensino do gênero na apropriação de determinadas capacidades de linguagem pelos alunos. Nessa direção, os autores descrevem e analisam os modos de produção de um debate, antes e depois da implementação de uma intervenção didática.

\footnotetext{
4 Especialmente em se tratando do contexto sociocultural brasileiro, em que os modos de acesso a práticas de exercício da palavra pública são desigualmente distribuídos, sendo a escola a agência por excelência em que crianças, jovens e adultos podem apropriar-se de gêneros orais formais e públicos como o debate.
} 
Finalmente, o estudo de De Pietro e Schneuwly (1999), ao analisar os modos com que os alunos se voltam para sua própria produção linguageira no contexto de atividades de ordem metalingüística centradas no gênero debate, busca discutir, de um ponto de vista ao mesmo tempo teórico, metodológico e epistemológico, o problema maior da transposição didática dos gêneros para as práticas didáticas. Os autores assinalam a importância do processo de modelização didática no ensino-aprendizagem de um gênero. A modelização permitiria, assim, a inscrição do gênero - investido de uma forma escolar - no sistema escolar de disciplinarização, o que traz implicações significativas no percurso de desenvolvimento dos alunos.

$\mathrm{Na}$ esteira das percepções dos autores mencionados, nossa contribuição neste estudo propõe descrever e analisar o processo de produção do gênero debate regrado enfatizando um dos três pólos que integram o "tri-

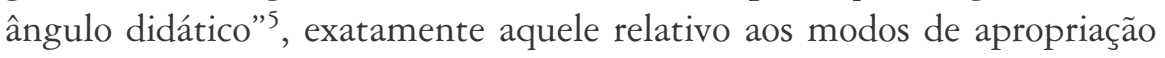
do gênero pelo aluno. Esse foco poderá permitir que discutamos pelo menos duas questões complementares:

(i) como os alunos se integram na tarefa de produção do debate regrado?

(ii) como avaliam a tarefa mencionada após a finalização do conjunto de atividades que visaram a ensinar o gênero debate?

Passemos à descrição dos modos de configuração do debate de que tratamos na dinâmica didática aqui considerada, bem como aos modos de constituição dos dados de que nos ocupamos.

\section{Descrevendo o processo de recepção-produção do debate como objeto de ensino}

O contexto didático em que se processou a recepção-produção do gênero debate articulou uma seqüência de atividades. Tais atividades ocorreram no terceiro bimestre letivo de 2005 - aproximadamente entre os meses de dezembro de 2005 e janeiro de 2006. Estivemos envolvidos na concepção e no tratamento didático dessas atividades na posição de professor da

\footnotetext{
5 O "triângulo didático" seria constituído pelo professor, pelos alunos e pelo objeto de ensino (ver,
} por exemplo, Schneuwly, Dolz e Ronveaux, 2005) 
turma, embora essa posição se tenha imbricado com a de pesquisador, uma vez que havia, desde a concepção da seqüência de atividades, o interesse em gerar dados de pesquisa sobre as práticas de apropriação de gêneros na escola ${ }^{6}$.

Embora estivesse explícita a proposta de que o debate seria o objeto de ensino-aprendizagem em que estariam centradas as atividades do bimestre, não houve uma modelização didática mais sistematizada do gênero. Mesmo a variante do gênero a ser considerada não estava explícita nos objetivos e nas atividades propostas. Os procedimentos didáticos implementados inspiraram-se, de modo bastante geral, na proposta de seqüência didática, tal como concebida por Schneuwly, Dolz e seus colaboradores (v. Schneuwly e Dolz, 2004).

Retivemos, particularmente, da proposta de seqüência didática os três momentos principais em que se configura o trabalho didático em torno de um gênero: um momento de produção inicial - que visa a diagnosticar o conjunto de saberes que os alunos já têm sobre o gênero -; um conjunto de atividades que visa a trabalhar as dimensões ensináveis do gênero com base nas necessidades e nas possibilidades de aprendizagem dos alunos - e, por fim, a produção final do gênero, ocasião que permitiria aos alunos o exercício do conjunto de saberes apropriados durante a seqüência.

\subsection{Os locutores, o tema e a seqüência de atividades}

A seqüência a que se refere este estudo foi proposta a uma turma de alunos adolescentes - na faixa etária entre 15 e 17 anos - da segunda série do Ensino Médio de uma escola pública de Belém (Pará). De modo geral, trata-se de alunos que vivem em um contexto urbano e que, ao longo de

\footnotetext{
6 Esse propósito de geração de dados insere-se no projeto de pesquisa "Modos de produção-recepção de gêneros discursivos em práticas didáticas de ensino-aprendizagem de língua" (Gomes-Santos 2006), que coordenamos. Entre os objetivos iniciais do projeto estavam: i) o registro, a descrição e a análise das atividades de ensino-aprendizagem da leitura, da produção textual e dos objetos gramaticais em aulas de língua; ii) a problematização de abordagens metodológicas de coleta, ordenação, descrição e análise de dados para a investigação sobre a linguagem em ambientes de ensinoaprendizagem, com vistas à constituição de banco de dados e iii) o estudo das implicações do trabalho didático-pedagógico centrado nos gêneros discursivos para a discussão sobre problemas relativos ao ensino de línguas.
} 
seu percurso de letramento escolar, tiveram não apenas acesso a informação como também a possibilidade de interagir em situações de uso formal e público da linguagem ${ }^{7}$.

O tema a ser debatido durante o bimestre letivo, escolhido pelo professor, girava em torno da polêmica de implantação do sistema de cotas para o ingresso de negros, pardos, indígenas e alunos de escola pública no ensino superior, projeto recém-aprovado, na época de realização da seqüência de atividades, pelo Conselho Superior da Universidade Federal do Pará (UFPA). Faltando apenas um ano para concluírem o Ensino Médio, os alunos encontravam-se diretamente envolvidos na discussão sobre o tema que, naquele momento, chegava mesmo aos meios de comunicação e produzia uma certa mobilização na comunidade escolar de todo o estado.

A seqüência consistiu na implementação das seguintes atividades, elencadas a seguir e descritas na próxima seção deste texto:

i) realização de um debate preliminar sobre o tema.

ii) atividades de apropriação de informações sobre o tema, de caracterização do gênero debate e de preparação do debate final, tais quais:

(ii.a) leitura individual ou em grupos de um conjunto de textos tratando do tema, extraídos da mídia impressa, e posterior discussão sobre mecanismos de argumentação neles presentes;

(ii.b) exibição de uma entrevista sobre o tema com o reitor da Universidade Federal do Pará, com posterior discussão sobre a entrevista;

(ii.c) exibição de dois debates - um tratando do tema e outro sobre tema diverso - com posterior discussão sobre eles;

(ii.d) exposição pelo professor sobre mecanismos de construção da argumentação em gêneros orais, principalmente no gênero debate.

\footnotetext{
A escola em que estudam - alguns deles desde a infância -, considerada campo de pesquisa e de estágio para os alunos em formação na Universidade Federal do Pará, proporciona momentos de discussão coletiva em sala de aula e o exercício relativo da fala pública, por meio de gêneros como a exposição oral, o comentário sobre textos etc.
} 
iii) realização de um debate final sobre o mesmo tema do debate preliminar.

iv) exibição dos debates produzidos pela turma e avaliação deles pelos alunos.

\subsection{Caracterizando as atividades}

Considerando que a seqüência de atividades de trabalho em torno do gênero debate configurou-se conforme os quatro momentos mencionados, cabe expor mais especificamente em que consistiram esses momentos. Os alunos iam sendo informados pelo professor, ao longo da realização da seqüência, das atividades que seriam posteriormente implementadas.

O debate inicial - ponto de partida da seqüência - ocorreu de modo mais ou menos espontâneo, o que significa dizer que os alunos foram convidados a debater sobre o tema proposto pelo professor sem que houvesse qualquer preparação anterior dos mesmos para essa atividade. O debate foi realizado logo após a leitura de um pequeno texto, extraído do jornal da Associação dos Professores da UFPA (ADUFPA), que informava sobre as discussões que se estabeleciam em torno da implantação do sistema de cotas na UFPA. A turma foi disposta em círculo e procedeu-se à escolha de um aluno que coordenaria a discussão e de outro que inscreveria aqueles que quisessem tomar a palavra, ordenando os momentos para cada fala segundo a ordem de inscrição. O debate durou cerca de trinta minutos e foi gravado em áudio-vídeo pelo próprio professor.

Um conjunto amplo de atividades foi proposto após a realização desse debate inicial. O que de comum as articulou foi o interesse de tornar tanto o gênero debate quanto o tema particular sobre o qual se debateria mais próximos dos alunos. Ou seja, as atividades visaram, de um lado, à coleta e ordenação de informações sobre o tema com vistas à sistematização de pontos de vista e de argumentos a serem retomados em momento posterior (durante a preparação e realização do debate final) e, de outro, ao reconhecimento de características gerais do funcionamento do gênero debate, relativas principalmente aos vários papéis que se pode assumir no debate (debatedor, mediador do debate, auditório), aos modos de exposição do locutor durante o debate (desde a postura corporal até a entonação, por exemplo), aos modos de construção da opinião (uso de dispositivos de ar- 
gumentação particulares, de um registro formal de linguagem) etc. É a atenção a esses aspectos que explica o procedimento de intervenção do professor durante ou ao final de cada atividade proposta: ao mesmo tempo em que enfatizava os aspectos relevantes a serem considerados nas atividades, ele convocava os alunos continuamente a emitirem comentários sobre as atividades e propunha mesmo algumas tarefas ou exercícios de verificação dos conhecimentos que eventualmente vinham sendo construídos pelos alunos.

A um dado momento da seqüência dessas atividades, o professor propôs à turma o início da preparação do debate que seria realizado ao final do bimestre letivo. Para tanto, foram definidos grupos nos quais os alunos foram, de modo aleatório, inseridos: (i) grupo favorável ao sistema de cotas; (ii) grupo de apoio aos favorável; (iii) grupo contrário ao sistema de cotas; (iv) grupo de apoio ao contrário; (v) grupo mediador do debate e (vi) auditório.

A proposição desses seis grupos teve por objetivo engajar a turma como um todo na preparação do debate, já que ele seria um dos principais instrumentos de avaliação do bimestre. A resistência de alguns alunos a sua inserção em um grupo com que não se identificavam no que se refere à opinião individual sobre o tema em questão foi contornada pelo professor: ele se dirigiu à turma explicando que, para os objetivos da atividade, muito mais importante do que a opinião pessoal de cada aluno, era a competência que poderiam demonstrar em assumir um papel, um ponto de vista, e torná-lo convincente a ponto de persuadir o outro-colega. Nas aulas que se seguiram à distribuição dos alunos nos grupos, esses últimos se empenharam na seleção e organização de argumentos conforme a posição que assumiriam no debate. Como instrumento de acompanhamento do trabalho dos alunos, o professor propôs um caderno de notas no qual cada grupo deveria registrar, a cada aula, as tarefas realizadas. São exemplos de registros no caderno de notas os que se seguem:

26/01/06 Hoje cheguei um pouco atrasado a sala de vídeo, onde retornamos para assistir a continuação do debate sobre a circulação e o comércio de armas de fogo no Brasil. A todo momento ouvimos comentários e opiniões do professor acerca dos recursos e meios utilizados pelos debatedores. Bem no final da aula não chegamos a assistir todo o vídeo no entanto conseguimos acompanhar a maneira em que é estruturado um debate. [CN1] 
30/01/06 Nos reunimos em sala de aula para dar início ao levantamento de dados para o nosso grupo (...). Vamos fazer uma enquête com a opinião das pessoas separando-as em grupos de idade e sexo conferindo também a porcentagem de favoráveis e contrários já tendo assim também alguns dados estatísticos. Realizamos enquetes também para coletar depoimentos com justificativas. [CN4]

O debate foi realizado ao final do bimestre, conforme previsto, teve a duração de aproximadamente 60 minutos e foi gravado em áudio-vídeo.

Nas aulas seguintes à realização do debate, foram propostas aos alunos duas atividades finais: i) a exibição dos dois debates (o preliminar e o final), com breve discussão sobre eles e ii) a avaliação das atividades do bimestre pelos alunos, por meio de uma ficha de avaliação proposta pelo professor. A atividade de avaliação foi realizada em duplas de alunos, eventualmente de modo individual.

\section{O debate regrado como objeto de pesquisa}

\subsection{Sobre as opç̃es metodológicas e a constituição do corpus}

Retomando a discussão com que iniciamos este estudo, diríamos que a investigação das práticas de apropriação de gêneros em contextos situados permite aproximações de ordem diversa em relação aos dados de pesquisa então gerados. Uma abordagem mais tipicamente lingüística desses dados permitiria, por exemplo, a discussão de questões diversas, a depender da tradição teórico-disciplinar em se inscrevesse o estudo: poder-se-ia, segundo uma abordagem textual-conversacional, tratar do problema da construção da referenciação no gênero ou, como sugere Mondada (1995, 2005), da construção interativa de "objetos-de-discurso". Muito se teria a dizer a esse propósito. Poder-se-ia, também, segundo uma perspectiva enunciativo-discursiva, tratar da questão dos processos de subjetivação dos sujeitos quando em situação de produção de um debate ${ }^{8}$. Nesses casos, o propósito é a descrição de determinadas práticas - constituídas em e mediadas por um gênero - e o foco da investigação é uma questão particular de linguagem.

\footnotetext{
8 Trata-se do tema que desenvolvemos em outro estudo, intitulado "Processos de subjetivação em práticas de recepção-produção de gêneros discursivos: questões de discurso e de ensino" (inédito).
} 
Sob uma perspectiva mais propriamente aplicada (diríamos mesmo didática), o foco de atenção passa a ser compreender como um gênero tal qual o debate adquire um modo de funcionamento instituído (Maingueneau 2004: 111) pela prática didática escolar, ou seja, como se investe de uma forma escolar (Thévenaz-Christen 2005). O tratamento dos dados, nesse caso, parece apresentar-se particularmente complexo ${ }^{9}$ na medida em que se faz necessário atentar para o estatuto plural em que se constitui o processo de recepção-produção do gênero na situação didática considerada: ao mesmo tempo em que um gênero como o debate, por exemplo, constituise em dispositivo de comunicação (Maingueneau 1998, 2004) de que dispõem os alunos para a discussão sobre um determinado tema, ele é também, e sobretudo, marcado por sua circulação na situação didática em que adquire o estatuto de objeto de ensino (Dolz e Schneuwly 2004). Em outros termos, seu modo de existência e de funcionamento é constitutivamente definido pelo fato de ser ele o objeto de ensino em torno do qual se ordenam as práticas de ensino-aprendizagem da língua.

No caso particular deste estudo, assumimos o pressuposto geral da necessidade de construção de um saber, por parte dos estudos da linguagem, especialmente dos estudos aplicados, sobre as práticas efetivas de uso da linguagem em contextos de ensino-aprendizagem da língua ${ }^{10}$, o que parece condição para, de um lado, complexificar a própria teoria dos gêneros do discurso e, de outro, propor intervenções didáticas adequadas ao real da instituição escolar. Nessa direção, essa dimensão intervencionista da pesquisa não seria apêndice, mas o vetor inspirador da reflexão científica, o centro em torno do qual se organizam os referenciais, procedimentos, bem como os recursos e instrumentos de investigação.

Dado esse pressuposto geral e considerando a diversidade de tratamentos possíveis dos dados, optamos por focar nossa atenção, como já mencionamos, na atividade do aluno, ou seja, nos modos com que se insere no processo de produção do gênero debate e em suas percepções sobre as

\footnotetext{
9 Ver seção 1, neste estudo.

10 Tal propósito vem sendo contemplado pelos estudos desenvolvidos pela equipe de Didática de Língua da Universidade de Genebra (v. Dolz e Schneuwly 2002; Schneuwly, Cordeiro e Dolz 2005), especialmente no projeto mais recentemente desenvolvido, intitulado "La construction de l'objet enseigné en classe de français. Analyse du travail enseignant en grammaire et en production écrite”.
} 
tarefas realizadas. Para tanto, dois conjuntos de dados constituirão particularmente nosso foco de interesse:

i) os debates produzidos pelos alunos - preliminar (DP) e final (DF);

ii) as 16 fichas de avaliação (FA) em que emitem suas percepções sobre o conjunto de atividades propostas ao longo do bimestre.

\subsection{Modos de apropriação do gênero: analisando o evento de produção do debate}

Um procedimento possível de abordagem do primeiro conjunto de dados de que dispomos seria aquele proposto por Dolz, Moro e Pollo (2000), que consistiria em comparar o debate inicial e o debate final produzidos no interior de uma seqüência didática, avaliando os efeitos que essa última produziu no processo de aprendizagem dos alunos, especialmente no que se refere ao uso de determinadas dispositivos de construção da argumentação. Entretanto, no caso do conjunto de dados gerados a partir da intervenção didática aqui considerada, tal procedimento não parece simples embora nos deva servir largamente de inspiração -, por duas razões que exporemos logo a seguir:

i) inicialmente, pelo fato de não ter havido uma seqüência didática centrada em determinados objetos a serem ensinados. Em outros termos, embora determinadas atividades didáticas tenham sido implementadas, não houve uma definição mais precisa das dimensões ensináveis do gênero que pudesse servir de parâmetro para uma eventual comparação entre os debates ${ }^{11}$;

ii) sintomático dessa ausência de uma modelização mais precisa do gênero é o fato de os dois debates terem naturezas e modos de funcionamento bastante diversos, como buscaremos mostrar a seguir.

\footnotetext{
11 Como exemplo, poderíamos mencionar a ausência de um trabalho mais direcionado para o papel do moderador, a que o modelo didático do debate regrado proposto pelos estudos mencionados atribui uma importância significativa, considerando-o princípio de regulação constitutivo do funcionamento do gênero.
} 


\subsubsection{Do debate preliminar}

No debate preliminar, os alunos foram dispostos em círculo e o tema foi lançado. Cada aluno, espontaneamente ${ }^{12}$, poderia tomar a palavra e emitir seu ponto de vista sobre o tema. Um aluno foi escolhido para coordenar a discussão, ou seja, distribuir a tomada de turno pelos colegas, e outro, para inscrever aqueles que gostariam de se manifestar. $\mathrm{O}$ foco da atividade linguageira dos alunos dirigiu-se, de modo geral, para a emissão de uma certa percepção sobre o tema, nem sempre marcada por um posicionamento particular (favorável ou contrário, por exemplo). É exatamente esse foco na construção temática, ou seja, na emissão de uma resposta (ainda em constituição, provisória) à questão em discussão - e não o alçamento do aluno a um papel, a uma posição particular, aquela de debatedor - que pode explicar a oscilação de seus posicionamentos quanto ao tema. O episódio transcrito ${ }^{13}$ a seguir ilustra esse aspecto do debate preliminar: a aluna, que vinha se manifestando favoravelmente ao sistema de cotas para o ingresso de negros na universidade, a um momento dirige-se ao professor (que efetuava a gravação) e pede a palavra para dizer que o sistema de cotas pode produzir um preconceito em relação às pessoas de pele branca.

15'19" AC: $\quad$ Lprofessor

15'20": P: $\quad$ [muito bem... pois não... quem é?

15'21" AC: é engraçado que as pessoas falam... da questão do preconceito com o negro... ah o negro vai ser cada vez mais discriminado... mas e as pessoas que não se enquadram nesse padrão... tem as condições... que são brancas... elas também não vão se sentir discriminadas mesmo por esse tipo $(\mathrm{xxx}) \ldots$ a questão do preconCEITO

\footnotetext{
12 Vale lembrar que o carater espontâneo de que se investiu esse debate preliminar materializa-se não apenas em termos mais propriamente verbais, mas também nos gestos, no modo de entonação, no registro de linguagem, enfim, nos modos de exposição corporal dos alunos (alguns mantêm-se recostos - inclinados na cadeira -, outros portam óculos de Sol durante sua intervenção etc.). Tratase da emergência de um ethos (Maingueneau, 2001) fundado sobre a espontaneidade.

13 As convenções de transcrição utilizadas foram as seguintes: ...: pausa pequena; $(+)$ : pauta longa; /: interrupção ou corte brusco da fala; [ ] : sobreposição de vozes; ::: alongamento forte de vogal; MAIÚSCULAS: alteração de voz com efeito de ênfase; (xxx): fala incompreensível; (( )): comentário do analista; /.../ corte na produção do locutor. Eventualmente, foram também utilizados sinais de pontuação gráfica, especialmente ponto de interrogação (?), bem como as convenções ortográficas do português. Os trechos sublinhados remetem à análise proposta pelo autor. Finalmente, quanto à referência aos locutores, as falas dos alunos são indicadas pela abreviação de seus nomes (quando não foi possivel identificar o aluno, assinala-se a fala com $\mathrm{Al}$ ). A do professor é indicada por $\mathbf{P}$.
} 


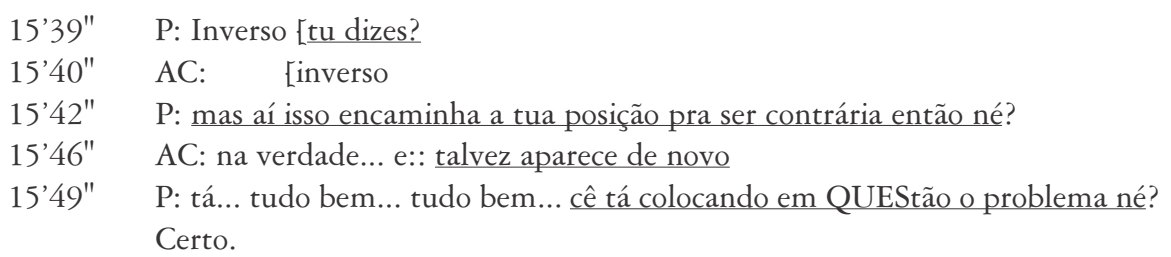

O interessante é notar a tentativa do professor de garantir uma certa coerência das posições que vinham assumindo os alunos, uma vez que questiona a oscilação do posicionamento da aluna - 15'42" P: mas aí isso encaminha a tua posição pra ser contrária então né?. A aluna, por sua vez, tem seu foco de atenção não em um posicionamento particular que pode ser defendido, mas na explicitação de uma terceira via de tratamento da questão em discussão: nem favorável nem contrário, talvez. O professor compreende de imediato esse movimento e o legitima - 15'49" P: tá... tudo bem... tudo bem... cê tá colocando em QUEStão o problema né? Certo.

Ainda em decorrência do foco na construção temática, um dos aspectos significativos do debate preliminar é a pouca presença de retomadas da fala do outro, seja para aderir a ela, seja para refutá-la, ou mesmo para reformulá-la. Embora as intervenções dos alunos guardem entre si um certo caráter interativo e, nessa direção, embora os pontos de vista expostos por alguns alunos pressuponham a opinião dos colegas, não há explicitação mais significativa de retomada dessa opinião, pelo uso inclusive de mecanismos lingüísticos que permitiriam essa retomada. O efeito de escuta do outro parece ser, nesse debate preliminar, sobredeterminado pela centração no tema, pela emissão de um comentário sobre ele, ou, melhor dizendo, pelo efeito de justaposição de comentários sobre ele. Os raros momentos de explícita retomada do comentário do outro são instigados pelo professor ${ }^{14}$ :

14 Não é inutil fazer referência a esse papel que assume o professor: ele é o centro em direção ao qual se voltam os alunos (a intervenção do aluno não raro começa com o vocativo professor). Embora pudéssemos afirmar, de início, que isso decorre do fato de ser ele quem segura a câmera e faz a gravação, há uma motivação outra, muito bem exposta na análise que propõem De Pietro, Erard e Kaneman-Pougatch (1997: 105) sobre a dinâmica das trocas em debates realizados antes de intervenções didáticas. Nos termos dos autores: "Mesmo o desenrolar dos turnos de fala se plasma, nesse exemplo [os autores mencionam um exemplo analisado], sobre o ritual de uma aula trivial: os debatedores levantam a mão antes de tomar a palavra, olham a professora, buscando sua aprovação, não se interrompem reciprocamente. A professora, cuja autoridade é fortemente interiorizada, torna-se de certo modo a condutora do jogo implícito, seu papel reduz-se a dar a palavra, a aprovar/desaprovar, a dar segurança. Assiste-se a um debate que se assemelha a um esquema em forma de estrela, em que a professora estaria 'apesar dela mesma' no centro". 
11'25" P: outros gostariam de se posicionar inclusive comentando o que o colega falou... algum colega comentou

11'32" AC: professor... bom eu falei da questão do do de não... dos alu/ da política de permanência de alunos que não poderiam se manter... é porque... a gente vê muito na Ufpa eh: alunos que abandonam o curso que era pra ser concluído em quatro ou cinco anos eu concluo eh: ficam por lá dez... até onze anos... então... qual é a causa de tudo isso ? então não existe uma política/ de permanência tão eficaz assim... eu acho $(\mathrm{xxx})$

12' P: Certo

$12^{\prime} 04$ PD: professor... eu queria comentar o que a Carol disse... porque mesmo que a gente... eu digo assim... eh: a gente come:ça estuDANdo maternal... passa o fundamental... fica no ensino médio (...)

12’48" P: Alguém mais gostaria de se posicionar?

Outros aspectos do debate preliminar ora considerado poderiam ser destacados, tais quais os assinalados por Dolz, Moro e Pollo (2000: 46-7). Ao analisarem debates realizados antes de intervenções didáticas, os autores destacam que "os papéis e as funções dos diferentes protagonistas são apenas fracamente distinguidos". Outros aspectos como a justaposição de tópicos temáticos e a presença pouco proeminente de retomada e discussão da posição do outro mostram, como assinalamos, que, nesse debate preliminar, o investimento principal dos alunos parece localizar-se na construção de um comentário sobre o tema, como se estivéssemos no contexto de gêneros próximos: seja daquele que se atualiza nas interações espontâneas que os alunos mantêm fora da sala de aula, o gênero conversação, seja de um outro, mais formal e mais freqüente em sala, o gênero secundário exposição oral.

\subsubsection{Do debate final}

No debate final, não apenas foram estabelecidos papéis particulares que deveriam assumir os alunos, como esses papéis foram definidos previamente à realização do debate, no início do processo de preparação do mesmo. Como dissemos, para esse debate foram definidos grupos nos quais os alunos foram, de modo aleatório, inseridos: (i) grupo favorável ao sistema de cotas; (ii) grupo de apoio aos favorável; (iii) grupo contrário ao sistema de cotas; (iv) grupo de apoio ao contrário; (v) grupo mediador do debate e (vi) auditório. Daí a cautela em se estabelecer um olhar comparativo entre esse e o debate preliminar. Isso não impede, entretanto, que possamos apresentar alguns modos de funcionamento do gênero com base naquilo que aparece como 
mais proeminente no evento. Ainda uma vez, as percepções de Dolz, Moro e Pollo (2000) são, a esse propósito, valiosas como parâmetro de observação.

O que se poderia apontar como bastante significativo no debate final é justamente a centração nos papéis, nos posicionamentos dos debatedores. Isso não significa obviamente que a discussão sobre a temática não tenha sido incrementada. É evidente que após a realização de um conjunto de atividades voltadas também para o tema, esse último tenha adquirido um outro perfil no repertório de conhecimentos dos alunos. É na conjunção desse novo perfil temático com o estabelecimento de papéis a serem assumidos durante o debate que são produzidos, entre outros, dois efeitos nos modos de apropriação do gênero pelos alunos: o efeito de escuta do outro e o efeito de coerência temática. Esses dois conjuntos de efeitos são materializados pelo uso de determinados dispositivos linguageiros de construção da argumentação. Assim, quanto ao efeito de escuta do outro, poderíamos destacar, por exemplo, os dispositivos de retomada do posicionamento do outro, seja para aderir a ele,

18'30" S: posso falar uma complementação?

18'32" P: Uhn uhn

18'33" S: é o seguinte... é:: só pra dar um exemplo em cima do argumento da: Jéssica... cin/ pelo que eu saiba... cinquenta é:: cinquenta é::... os alunos que entrarem pelo sistema de cotas... terão... uma pontuação cinqüenta e quatro por cento menor no Vestibular /.../

seja para refutá-lo.

07’07" K: a: sem dúvida a opinião do Felipe ele/procede né:... só que: não não foi feita uma análise tão crítica da sociedade afinal de conta ele tem que se/ levar em consideração... que sociedade nos vivemos... a sociedade BRASILEIRA /.../

08'47" A: bem... como o Kauê disse é um proBLEma que vem desde da base... não adiANta a gente cheGAR... e bo/implantar um sistema de cotas que vai é:: quem entra a partir do sistema de cotas reduz... basTANTE a nota ou seja a pessoa esta sendo... avaliada de uma forma menos criteriosa o que vai prejudicar as questões/os/a formação de bons profissionais no Brasil /.../

A refutação, nesses casos, supõe um acordo inicial em relação à opinião do outro para, em seguida, encenar uma oposição a essa opinião ${ }^{15}$.

15 De Pietro, Erard e Kaneman-Pougatch (1996/7: 107) detectam o mesmo fenômeno nos debates que analisam. 
A operação de refutação é, com efeito, das que mais se diversificam. Além dos excertos mencionados, há casos em que a refutação ocorre de modo direto,

15'58" P: bom rebatendo o que a Sarah faLOU o sistema de cotas... ele não exclui ou ele discrimina... os grupos étnicos... ele simplesmente faz com que tu mesmo é: escolha é:: a tua: etnia /.../

ou em que atua na direção de deslegitimação do argumento do outro,

42'64" D: a gente ver $(\mathrm{xxx})$ a gente ver a a diferença da enquete ... principalmente porque... eles tão/ fizeram (xxx) numa escola particular numa/ num cursinho particular que é o Supremo... e fizeram no Cefet... o Cefet... a gente não pode falar que é uma escola publica... o Cefet é PUblico... mas ele é um/ é:: é tipo uma universidade profissionalizante /... /... então... a gente não pode dizer que que a que a opinião deles é a opinião de uma escola publica... se eles forem numa escola publica... publica... eles vão ver que é dife/ que que que:.... que a realidade é outra que muita gente vai achar... vai ver que... o sim vai... senão equilibrar vai passar

ou ainda em que atua como coação injuntiva:

16’38" F: [é o grande erro das cotas... uma coisa na FRENTE... o problema não está na FRENTE ((girando o braço para a frente))... e eu espero que você concorde comigo... o problema não esta na frente... ele (sempre) ta atrás ((girando o braço em retorno))... a o: o governo não tem que olhar para o (futuro) /.../

No que se refere ao efeito de coerência temática, ele supõe a vinculação dos argumentos à posição assumida, bem como uma certa constância dessa vinculação no percurso de produção do debate, como podemos identificar nos excertos a seguir.

35'29" J: (xxx) fui citada... eu queria ressaltar com com o NAYron que ele foi feliz no argumento dele... ele disse que... ((barulho na turma)) eu queria repetir NAYRON o que foi que eu falei... eu disse que:: o: os alunos né que forem beneficiados pelas cotas ... eles vão/ tem que ter o ensino médio né?... em escola pú:blica /.../

48’49" K: Retornando à:: minha antiga fala ((o aluno ajeita seus papéis. A turma ri))... é: gostaria assim que/ a::... foi colocado por alguns dos integrantes... do grupo oposto... que::... sobre permanência da::... (xxx) estudantes... de escola/ de escolas publicas ou seja/ aqueles de baixa renda... que:: não tiveram/... grande oportunidade de estudos /.../ 
A coerência temática pode ser construída pela retomada de discursos de autoridade (seja aqueles fundados no saber acadêmico-científico, seja nos que se fundam na experiência). Essa retomada atua como legitimadora do posicionamento do debatedor em relação ao tema.

10'39" U: (xxx) é porque:: teve uma pesquisa na USP pelo IBGE que diz que... os/os que entraram pelas/pelas cotas... eles... não... não quer dizer que eles vão ter um rendimento meNOR do que os que não entraram pelas cotas na universidade $/ . . . /$

11'35" K: ahn: (xxx) eu gostaria de mostrar agora os gráficos referentes a:: população brasileira e: os índices de: desenvolvimento humano(xxx) (étnicos)... ahn: (xxx) negros pardos e (xxx) ((o aluno se levanta e se dirige ao retroprojetor; os demais alunos conversam entre si))

31'19" APC: /.../ e eu consegui um depoimento de uma garota... uma estudante de cursinho... e ela fala assim... ela começa o depoimento dela falando uma frase assim $(($ lendo))... sou negra mas não sou burra... fala sério... isso é ridículo... se eles tão pensando que com isso vai acabar com o racismo estão muito enganado... estou revoltada com essa situação... eles estão praticamente humilhando nós negros como se a gente não tivesse capacidade de passar em uma federal como qualquer outro aluno... fico revoltada quando começam a separar negro de branco... poxa nós somos pessoas comuns e normais... e temos SIM a capacidade de passar em uma faculdade sem/ si sem sem precisar dessa porcaria de cotas... ela é NEGRA gente NEGRA NEGRA o pai negro a mãe negra... só que ela é totalmente contra... ela tá se sentindo rejeiTAda... eu concordei com ela... entendeu?... e eu e eu por eu/ também ta/ daqui a: para o ano eu vou fazer faculdade... eu tou so/ sou totalmente por causa disso porque... POXA... e a gente que tá estudando como é que fica?... dez por cento das vagas é praticamente... não que eu esteja dizendo que eu não consiga... mas que é difícil... essa é minha opinião

Parece ser, portanto, o pré-estabelecimento de papéis a serem assumidos que produz os dois efeitos mencionados - de escuta e de coerência temática - no debate final. É ainda a conjunção desses efeitos que funda o estatuto mais propriamente escolarizado desse debate. Assim, supondo-se que a intervenção didática ocorrida entre os dois debates tenha produzido efeitos no processo de apropriação do gênero pelos alunos, podemos dizer que esses efeitos se referem à forma escolar de que o debate final, mais explicitamente do que ocorre no debate preliminar, se investe. Essa forma escolar tem uma eficácia institucional: ela funda (e ao mesmo tempo legitima) 
as condições de pertinência do gênero a uma disciplina escolar particular Língua Portuguesa -, o que supõe, entre outras implicações ${ }^{16}$, que:

i) ele é apropriado em um evento constitutivamente diverso daqueles em que seria apropriado fora da escola, ou seja, a forma escolar implica em uma ruptura com o quotidiano;

ii) ele se torna passível de segmentação [élémentarisation ou disconnexitéł em dimensões que podem ser objeto de ensino-aprendizagem;

iii) ele integra um desenho curricular mais amplo, que inclui uma certa programação de conteúdos, além de procedimentos e instrumentos de avaliação;

iv) ele adquire uma forma textualizada (em geral, um caráter escritural), ou seja, materializa-se em textos que permitem sua circulação e seu reconhecimento públicos.

Complementarmente, é a forma escolar de que se investe progressivamente o gênero debate na situação didática aqui considerada que permite as condições de estabelecimento de um distanciamento em relação a ele, de um saber sobre ele, e as condições para se poder falar dele ${ }^{17}$. Essa possibilidade de distanciamento dos alunos de sua atividade linguageira e de construção de uma percepção sobre ela (e sobre o gênero produzido) aparece marcada nas avaliações que fazem (nas fichas de avaliação) das tarefas em que foram envolvidos.

\footnotetext{
16 As considerações sobre a noção de forma escolar são creditadas a Bernard Schneuwly, em conferência intitulada "Genres et forme scolaire: enseignement e apprentissage de la langue première à l'école", durante a abertura da Jornada de Estudos "Corpus et Genres: apport des grands corpus pour la caracterisation des genres scolaires”, em 10/06/2006, na Université Paris X, em Nanterre (FR).

17 A prática de avaliação do debate que estabelece um distanciamento em relação a ele como forma de poder avaliá-lo não é exclusiva de situações didáticas. Essa mesma prática, com outros objetivos, é freqüente, por exemplo, na esfera política, em que os candidatos ou suas assessorias revêem muitas vezes o debate realizado com o objetivo de avaliar a participação do candidato para prepará-lo melhor para debates posteriores. No caso do debate de que tratamos, a postura de avaliação pelos alunos de sua participação no debate é particularmente significativa porque, como veremos logo adiante, extrapola a tarefa escolar mais específica que foram convocados a realizar, especialmente se considerarmos que a possibilidade de os alunos avaliarem as atividades escolares a eles propostas não parece corrente na tradição escolar brasileira. Agradeço a Jacqueline Barbosa por ter chamado a atenção para essas questões.
} 
Nas respostas às questões propostas na ficha ${ }^{18}$, os alunos reconhecem e enunciam as diferenças entre os dois debates, embora essas diferenças tenham sido antecipadas, de um certo modo, pelo professor ${ }^{19}$. Quando instigados a comparar os debates, os alunos apontam diferenças do primeiro em relação ao segundo em termos de: a) aprofundamento temático (opiniões baseadas em fontes de informações, pesquisa etc., o que garantiu maior credibilidade a elas); (b) estabelecimento de regras, o que garantiu um caráter mais formal ao debate e (c) o estabelecimento de papéis (mediador, auditório, grupo contrário e favorável).

O primeiro debate foi algo mais descontraído, onde foram desconsideradas regras, organização em grupos e a função destes grupos. Pode-se dizer que foi mais um bate papo aberto, em que foram expostas idéias não muito firmes (seguras) com relação ao tema. [FA6]

Foi um tanto quanto superficial. Algumas pessoas não definiram seus argumentos e decisões, pois não havia embasamento temático da maioria da classe. [FA10]

Acreditamos que não houve um debate propriamente dito, pois podemos perceber que os argumentos utilizados foram expostos com pouca base, ou seja, sem um domínio maior do assunto. Outra coisa que conseguimos captar foi o fato de não haver lado favorável e nem desfavorável, fazendo com que não houvesse uma discusão maior, parecendo apenas uma exposição de idéias. [FA16]

As diferenças apontadas pelos alunos remetem a uma distinção mais ampla, enunciada anteriormente: a distinção entre uma maior centração

18 A ficha é composta de três questões:

1. Como você caracterizaria o primeiro debate levando-se em conta aquilo que você define como um debate?

2. Qual sua opinião sobre o segundo debate no que se refere:

(a) aos argumentos levantados?

(b) ao modo com que os participantes apresentaram as opiniōes e os pontos de vista?

(c) aos recursos de argumentação utilizados pelos participantes?

3. Comparando os debates.

(a) Quais diferenças você apontaria entre os dois debates?

(b) Como você avaliaria as tarefas realizadas neste bimestre? O que você conhecia e o que passou a conhecer sobre o "debate oral"?

19 Nas instruções que antecedem as questões propostas aos alunos na ficha há uma caracterização dos dois debates, além da rememoração do momento em que ocorreram (início e final do bimestre) e das atividades que precederam o debate final: "A atividade proposta a seguir visa a avaliar o processo de construção do debate oral. Durante o bimestre, realizamos dois debates orais: o primeiro ocorreu no início do bimestre, de modo mais ou menos espontâneo; o segundo ocorreu já ao final do bimestre, depois de um conjunto de atividades. Ambos tiveram como tema a questão do sistema de cotas para o ingresso no ensino superior. São eles que serão objeto de nossa avaliação neste momento". 
no tema (na exposição de idéias), no caso do debate preliminar, e uma maior centração nas regras de funcionamento (no estabelecimento de papéis), no caso do debate final.

No primeiro debate, podemos caracterizá-lo como debate, porque debatemos e podemos [pudemos] expor nossas idéias individualmente, porém não tivemos uma organização digna de debate, pois não havia uma organização tanto na ordem como nas idéias a serem expostas [FA7]

Apareceu como algo característico em que se levou em conta a opinião pessoal dos debatedores e não a defesa de um segmento a ser defendido, ou seja, sim ou não, contra ou a favor. Não houve a necessidade de se obedecer regras estabelecidas se configurando mais como um espaço para a expressão de livres idéias. [FA8]

O debate foi como uma exposição de idéias sem muitas defesas como no segundo que já impôs a sua idéia mais ostensivamente. [FA 13]

Finalmente, uma última ocorrência traduz bem a percepção de um dos elementos caracterizadores da forma escolar em que se plasmou o processo que vai da produção do debate inicial até a produção do debate final: esse último pode ser considerado mais regrado não apenas em função da regulação interna (local) de seu funcionamento, mas também em função da regulação que se opera em outro nível, aquele do sistema escolar em relação ao que se espera do aluno em termos de aprendizagem, regulação essa que se materializa nos instrumentos de avaliação.

As principais características são que no primeiro debate as informações ainda não eram concretas, pois não existia uma pesquisa especifica sobre o assunto, no segundo debate já existia a pesquisa e foram usados vários tipos de recursos como estatísticas, números, havia mediadores e um tempo determinado para falar, no segundo debate estávamos sendo avaliados, com o nosso poder de argumentação.

\section{Considerações finais}

Retomando as considerações anteriormente expostas, diríamos que o percurso que vai da realização do debate preliminar à produção do debate final constitui-se - em decorrência de razões diversas, entre elas, da própria intervenção didática - como incremento da capacidade não apenas de debater sobre um determinado tema, de expor idéias sobre ele, mas de debater a partir de uma determinada posição. Do ponto de vista da aprendizagem, essa diferenciação parece significativa porque aponta para o 
desenvolvimento da capacidade do aluno de não apenas enunciar em situações formais, mas de reconhecer de que lugar enuncia, ou seja, de se distanciar de sua própria atividade linguageira (e daquela do outro) para, como sugeriria Bakhtin/Volochínov (1929), não refletir mas refratar os objetos do mundo, e se posicionar frente a eles. O desenvolvimento dessa capacidade, em última instância, parece ser uma das tarefas da instituição escolar.

Um excerto do debate final sintetiza de modo significativo o que dissemos.

62'45" A: é que: como adolescente eu acho que os adolescentes que lutam por justiça e: querem ser... verdadeiros... eu quero ser verdadeira... eu sou a favor das cotas ((risos e aplausos da turma)) (++) não quer dizer que seja inválido tudo o que a gente falou mas não existe esse negócio de fazer uma revolução primeiro no ensino porque é/ não adianta (esperar) crescer o bolo pra depois dividir... porque o Brasil tá crescendo há anos e até agora não foi dividido esse bolo... e:: eu quero parabenizar essa $(\mathrm{xxx}) \ldots$ porque isso é resultado de uma LUTA... e:: não adianta falar que:: é discriminada cotas pros negros porque existe cotas pros brancos se vocês forem reparar na nossa sociedade... porque preferem os brancos... preferem sempre os brancos que o negro... é só isso

A fala transcrita acima ocorre logo após a finalização do debate. A aluna toma de modo apreensivo a palavra - 62'42" A: eu queria falar uma opinião minha rapidinho -, olha fixamente para a câmera e enuncia que, embora tivesse assumido durante todo o debate a posição contrária à política de cotas, era favorável a essa política, e dizia aquilo porque "queria ser verdadeira". Embora essa manifestação da aluna pudesse ser mais ou menos esperada, uma vez que os papéis dos debatedores foram, como mencionamos, definidos aleatoriamente, o significativo em sua tomada de turno é o fato de ela reconhecer a existência de um "contrato didático" (Brousseau 1988; De Pietro \& Schneuwly 1999: 49) e, segura de que o ritual de produção do gênero chegara ao final, agregar à posição de aluna uma outra: a posição de adolescente que quer ser verdadeira. Isso parece indiciar aprendizagem.

A esse propósito, a citação a seguir é particularmente esclarecedora:

(...) a forma escolar plasma-se por uma série de determinações, como a ruptura entre a experiência quotidiana e a experiência escolar; a necessidade de apresentação progressiva dos conteúdos segundo uma lógica que não é mais aquela do desenvolvimento espontâneo, mas uma lógica pelo menos parcialmente definida pelos conteúdos 
ensinados; a necessidade de uma certa disciplinarização das matérias. Trata-se de condições que permitem o acesso a uma série de modos de pensar e de falar que são escolarizados e que pressupõem uma distanciação em relação aos processos psíquicos que os subjazem: distanciação quanto à linguagem, distanciação quanto ao pensamento, distanciação igualmente quanto à memorização etc. Nessa perspectiva, as formas escolares não aparecem, tal qual comumente se supõe, como um fator que impede o desenvolvimento, como obstáculos, mas como condições necessárias à construção de determinadas capacidades psíquicas, especialmente aquelas ligadas ao domínio de certas técnicas culturais como a escrita, o exercício científico ou a aprendizagem de línguas estrangeiras, pelo menos no que diz respeito a alguns de seus aspectos (De Pietro e Schneuwly, 1999: 53).

Para concluir, diríamos que o investimento em estudos que descrevam e interpretem práticas de ensino-aprendizagem da língua portuguesa em contextos socioculturais particulares pode trazer, além das implicações de ordem teórica, metodológica e aplicada mencionadas no início deste texto, subsídios para a reflexão sobre os contornos históricos de constituição da língua portuguesa como disciplina escolar, ou seja, sobre seu processo de disciplinarização ${ }^{20}$. Em outros termos, pode subsidiar a compreensão das determinações de ordem diversa que atuam na constituição dos saberes e dos discursos sobre a linguagem e sobre o ensino de língua, o que implica um dos primeiros passos para se pensar, em instâncias institucionais legitimadas para tal, em políticas públicas de incremento do ensino, de avaliação e elaboração de recursos didáticos e de formação de professores, especialmente em se considerando as práticas de ensino-aprendizagem da língua que se atualizam em contextos socioculturais (a Amazônia incluída) aos quais historicamente nem sempre foi garantido o direito de participação no debate sobre o que é ensinar português na escola quando se pretende efetivamente ensiná-lo.

Recebido em novembro de 2006.

Aprovado em abril de 2007.

E-mail:sandovalnonato@hotmail.com

\footnotetext{
20 Entre as várias portas de entrada possíveis para a compreensão desse processo está o importante investimento em pesquisas em estado da arte, que buscam definir os contornos históricos de constituição das disciplinas escolares - em nosso caso, a disciplina língua portuguesa - com base na problematização da produção acadêmica que delas se ocupa (ver, a esse propósito, o estudo que propusemos sobre a produção acadêmica paraense (Gomes-Santos, 2005c)).
} 


\section{ReferênCias Bibliográficas}

Bakhtin, M./Volochinov, V. N. 1979. Marxismo e Filosofia da Linguagem: problemas fundamentais do método sociológico na ciência da linguagem [1929]. São Paulo: Hucitec.

Bakhtin, M. 2003. Os gêneros do discurso. In: Estética da Criação Verbal [1952-3]. São Paulo: Martins Fontes.

Bronckart, J.-P. \& Plazaola Giger, I. 1998. La transposition didactique. Histoire et perspectives d'une problématique fondatrice. Pratiques, 9798: 35-58.

Brosseau, G. 1988. Le contrat didactique: le milieu. Recherches en Didactiques des Mathématiques, vol. 9, no. 3: 310-336. Paris: Editions La pensée sauvage.

Chevallard, Y. 1985. La transposition didactique. Grenoble: La Pensée Sauvage.

De Pietro, J.-F., Erard, S. \& Kaneman-Pougatch, M. 1996/7. Un modèle didactique du débat: de l'objet social à la pratique scolaire. Enjeux, 39/ 40: 100-129.

De Pietro, J.-F. \& Schneuwly, B. 1999. Maîtriser un genre textuel en contexte scolaire: concepts, notions et démarches. Actes des Journées d'Etude. Paris: GEPED - Université Paris VII-Denis Diderot: 41-59.

De Pietro, J.-F. \& Schneuwly, B. 2003. Le modèle didactique du genre: un concept de l'ingénierie didactique. Les cabiers THEODILE. Lille: Université Charles-de-Gaulle, no. 3: 27-52.

Dolz, J., Moro, C e Pollo, A. 2000. Le débat régulé: de quelques outils et de leurs usages dans l'apprentissage. Repères, 22: 39-59.

Dolz, J., Ronveaux, Ch. \& Schneuwly, B. (no prelo). Le synopsis - un outil pour analyser les objets enseignés. In: M. J. Perrin \& Y. Reuter (orgs.). Les méthodes de recherche en didactique. Actes du Premier séminaire international de juin 2005. Villeneuve d'Ascq: Presses Universitaires du Septentrion.

Dolz, J. \& Schneuwly, B. 1998. Pour un enseignement de l'oral. Initiation aux genres formels à l'école. Paris: ESF éditeur.

.2002. La construction de l'objet enseigné en classe de français. Analyse du travail enseignant en grammaire et en production écrite (Projet de Recherche). Section de Psychologie et Sciences de l'Education Université de Genève. 
Gomes-Santos, S. N. 2004a. A questão do gênero no Brasil: teorização acadêmicocientífica e normatização oficial. Tese (Doutorado em Lingüística). Instituto de Estudos da Linguagem, Universidade Estadual de Campinas.

.2004b. A circulação de saberes no domínio acadêmico-científico: o conceito de gênero em/como questão. In: A. Covre (org.). Quimera e a peculiar atividade de formalizar a mistura do nosso café com o revigorante chá de Bakbtin. São Carlos (SP): Grupo de Estudos dos Gêneros do Discurso - GEGE, p. 37-62. 2005a. A circulação de saberes no domínio dos estudos da linguagem brasileiros: por que o conceito de gênero e não outro em seu lugar? Sínteses, v.10: 217-231. Campinas (SP): Instituto de Estudos da Linguagem, Universidade Estadual de Campinas. . 2005b. "Preciso me manter imparcial": saberes sobre gênero em práticas de letramento escolar. In: Triboluminescência - Gegelianos e Bakhtin: ainda à sombra. São Carlos (SP): Editora do Grupo de Estudos dos Gêneros do Discurso (GEGE): 219-242.

. 2005c. Das relações entre linguagem e ensino de língua: a produção acadêmica paraense em foco. In: Moara, no. 24: 47-69. Revista do Programa de Pós-Graduação em Letras da Universidade Federal do Pará. 2006. Modos de produção-recepção de gêneros discursivos em práticas didáticas de ensino-aprendizagem de língua. Projeto de Pesquisa (Programa de Auxílio ao Recém-Doutor - PARD), Pró-Reitoria de Pesquisa (PROPESP) - Universidade Federal do Pará.

Maingueneau, D. 1984. Genèses du discours. Liège: Mardaga. .2001. Analyser les textes de communication. Paris: Natan. 2004. Retour sur une catégorie: le genre. In: J.-M. Adam, J.-B. Grize e M. Ali Bouacha (orgs.). Texte et discours: catégories pour l'analyse. Dijon (FR): Editions Universitaires de Dijon: 107-118.

MondaDA, L. 2005. A referência como trabalho interativo: a construção da visibilidade do detalhe anatômico durante uma operação cirúrgica. In: I. G. V. Koch, E. M. Morato \& A. C. Bentes. Referenciação e Discurso. São Paulo: Contexto: 11-31.

Mondada, L. \& Dubors, D. 1995. Construction des objets du discours et catégorisation: une approche des processus de référenciation. In : A. Berrendonner \& M.-J. Reichler-Beguelin (eds.). Du sintagme nominal aux objets-de-discours. Neuchâtel: Université de Neuchatel: 273-305. 
Rojo, R. H. R. 2001a. Modelização didática e planejamento: duas práticas esquecidas do professor? In: Kleiman, A. (org.). A formaçãa do professor - perspectivas da Lingüística Aplicada. Campinas, SP: Mercado de Letras: 313-335.

(org.) 2001b. A prática de linguagem em sala de aula - praticando os $P C N$ s. São Paulo: EDUC; Campinas, SP: Mercado de Letras.

. 2001c. A teoria dos gêneros em Bakhtin: construindo uma perspectiva enunciativa para o ensino de compreensão e produção de textos na escola. In: B. Brait (org.). Estudos enunciativos no Brasil histórias e perspectivas. Campinas (SP): Pontes; São Paulo: Fapesp: 163-85.

Schneuwly, B. 1995. La transposition didactique. Réflexions du point de vue de la didactique du français langue maternelle. In: J.-L. Chiss, J. David \& Y. Reuter (orgs.). Didactique du français, états des lieux. Paris: Nathan, 1995: 47-62.

Schneuwly, B. e Dolz, J. 2004. Gêneros orais e escritos na escola. Campinas, SP: Mercado de Letras.

Schneuwly, B., Cordeiro, G. S. e Dolz, J. 2006. A la recherche de l'objet enseigné: une démarche multifocale. Les dossiers des sciences de l'éducation, 14: 77-93.

Thévenaz-Christen, T. 2005. Les prémices de la forme scolaire - études d'activités langagières orales à l'école enfantine genevoise. Thèse (Doctorat en Sciences de l'éducation), Faculté de Psychologie et des Sciences de l'Education - Université de Genève, 439 p. 